\title{
Governance and Higher Education in Pakistan: What Roles do Boards of Governors Play in Ensuring the Academic Quality Maintenance in Public Universities versus Private Universities in Pakistan?
}

\author{
Sidra Usman ${ }^{1}$ \\ ${ }^{1}$ Department of Political Science, London School of Economics and Political Science, United Kingdom \\ Correspondence: Sidra Usman, Lahore Grammar School, 55 Main Gulberg Lahore, 54600, Pakistan. Tel: \\ 0092-302-4337751. Email: sidrasd@gmail.com \\ Received: February 10, 2014 \\ Accepted: March 5, 2014 \\ Online Published: March 7, 2014 \\ doi:10.5430/ijhe.v3n2p38 \\ URL: http://dx.doi.org/10.5430/ijhe.v3n2p38
}

\begin{abstract}
There are major structural issues in the higher education system in Pakistan leading to poor governance of institutions and questionable quality of education. This paper looks at the differences in the role of boards of governors in maintaining quality of education in both the public and the private sector universities in Pakistan. After having conducted qualitative research by interviewing selected academics and by secondary research, the problems in the governance of higher education in the country were identified. Governance in higher education is then analyzed in terms of the Boards of Governors of universities and their role and the overall management and organizational structure of the higher education institutions in both sectors. This paper further explores the role of the Higher Education Commission of Pakistan as a regulator of higher education in the country and its policies regarding quality assurance. This discussion helps in identifying the differences that are present in the governance structures of universities in both sectors. The result has been that the private sector boards portray a more efficient system compared to the public sector boards that lack autonomy and are under strong political influence. The recommendations that have been made require for a change in the organizational structures of boards in the public sector and increased checks by the HEC to promote good governance and quality assurance in universities in the country.
\end{abstract}

Keywords: Governance, Quality of education, Boards of governors, Quality assurance, Higher education

\section{Introduction}

Pakistan is a developing country at the verge of political and economic uncertainty. This uncertainty has spread to different sectors and institutions and the higher education sector is not hidden from it. The country has progressed slowly in terms of higher education over the years. After partition in 1947, Pakistan had only one public university, the Punjab University in Lahore and there was no private university at the time.The major increase in the number of universities in both the public and private sector has happened in the last three decades. With this rapid growth the number of universities has increased but at the same time the education quality was not checked(Hoodbhoy, 2009).

This led to a rising concern among academics and other stakeholders about the level of quality that was being provided by universities in the country. Questions arose about the governance and management of the higher education institutions especially in the public sector (Bilal \& Khan, 2012).

In 2000, the World Bank and UNESCO Task Force on Higher Education and Society compiled a report on the future of higher education in the developing world. After this report in 2000, reform efforts for higher education in Pakistan gathered pace in 2001. A Task Force for Improving Higher Education (TF) and a Steering committee on Higher Education (SCHE) started the movement for reforms in the country in 2001. Unfortunately this positive change came to halt within two years due to the resistance of the Vice Chancellors who lacked vision and proper understanding of the education system in the country(Gilani, 2006).

However, some of the suggested reforms in the report that was generated by the Task Force in Pakistan suggested the formulation of an independent regulator of higher education in the country. Thus, the University Grants Commission in Pakistan was converted to the Higher Education Commission (HEC) in 2002 (The Task Force, 2002). 
The regulator has since then created a quality assurance division to see the workings of universities and to see what else is required to get them to the level of international universities (Quality Assurance Division, HEC, 2011).However, the regulator acts as an external source to check and provide quality assurance mechanisms, internal controls are also required. This leads to the overall organizational structures of universities and the role of the top management, the board of governors of universities in both the public and the private sector.

The focus of this paper is to analyze the role of Board of Governors of universities and to what extent they play a role in the quality assurance of higher education in both the public and private sectors. It will also be seen if there is any difference between the two sectors in terms of the structures of boards, the level of autonomy they have and the quality assurance checks by the Higher Education Commission.

\section{Literature Review}

\subsection{Universities as 'organized anarchies' and the Garbage Can Model of Organizational behavior}

Universities are complex organizations. In a country like Pakistan, where there is still a continuous process going on in improving higher education institutions, decision-making at the highest level is the key to success.

The complexity of universities characterizes such organizations as a form of organized anarchy. What this means is that these organizations follow a complex system of decision-making. Organized anarchies are defined by three decision situations and they are: problematic preferences, unclear technology and fluid participation (Cohen et. al, 1972).

In order to understand universities as organized anarchies, the concept of an organized anarchy needs to be explored a little further. There are two main ideas that are important in the understanding of anarchy. The first is when organizations make chances without any consistent shared goals. It is common for complex organizations where decision-making is done under uncertain goals (Cohen et al, 1972).

In universities in Pakistan there is a degree of uncertainty when important decisions are being made. There is a clear-cut misunderstanding between the goals that are set by the top management and what is actually implemented. This results in a lack of proper governance and the university on the verge of a disoriented path.

The second thing for organized anarchy is the way the members of the organization are motivated. This leads to the idea as to how sporadic members of the organization become motivated and how they direct the attention, towards, or away from a certain decision (Cohen et al, 1972).

This too is a major driving force in decision-making in higher education institutions in Pakistan in both the public and the private sector. The level of motivation of the top management derives the quality of decisions that are made in the running of universities. As there is a lack of autonomy in the public sector the decisions are made favoring a political agenda rather than in helping to improve the overall governance issues of universities.

In universities in Pakistan both in the public and the private sector, the issues of higher education are related to a lack of proper decision-making. The 'Garbage Can Model' of organizational choice generally can be used in decision-making in higher education. Although the implication of the model varies in different universities and countries, it still provides a basic framework (Cohen et al, 1972).

The Garbage Can Model can be explained by understanding the processes within an institution. What this means is that a choice opportunity should be considered as a garbage can into which the members of the organization can dump different kinds of problems and solutions as soon as they are thought of. This process depends on the number of cans available and the different labels given to them. In the simplest form, in the garbage can model, a decision is the result of several impartial sectors in the organization (Cohen et al, 1972).

Higher education institutions in Pakistan lack proper leadership and hence has frayed decision-making. The issue of governance as discussed is the main problem in the lack of clear decision-making.

The garbage can model is a way to move past a detailed explanation of governance to a simpler one. This model investigates the ways of governance, which is less governed by authority and hierarchy. The basic idea driving this model is that rather than having an expected outcome, the decisions in a lot of the situations are the result of unanticipated convergence of opportunities, individuals and ideas (Peters, 2002)

There is an interrelated phenomenon between this model that can be used to describe the decision-making in universities and the level of governance as well. 


\subsection{Governance and Higher Education}

"Governance in higher education refers to the way in which institutions are organized and operate internally and their relationships with external entities with a view to securing the objectives of higher education as a realm of enquiry and critique." (Harvey, 2004-11)

Kohler (2006) proposed an approximate definition of (good) higher education governance as:

that institutional set-up and those processes at strategic level of both higher education and research institutions and of national and international systems which are concerned with the identification, validation, and realisation of those prerequisites and consequences and of that culture and those steering devices which pertain to institutional autonomy and individual freedom in their contexts with public responsibility of the institution to be governed, and which must be described and developed for the sake of maintaining and enhancing benefits with regard to the well-being of individuals and society, traditional academic values and objectives, quality and quality assurance, institutional positioning, effectiveness and efficiency of mass higher education and advanced research in democratic societies based on expert competence, on inclusion and participation, on the rule of law, on the freedom of ethically responsible individuals, and on mutual respect and - to add the notion of "good" governance to the definition of governance of higher education as such - serves these objectives best and at least to an optimum of compromise between conflicting aims and devices.

Kohler's definition of 'good' governance in higher education gives an idea of what is required for higher education institutions to have proper governance and management. Higher education institutions are very complex and there is a need to recognize the weak issues that lead to a lack of proper governance in both the developed and the developing countries.

It is an attribute of modern times that whenever there is talk of governance of higher education, there is an implicit reference to the governing boards of the universities, how they work, the relationship that is present between governance and management which is in fact the relationship the boards of governors with the CEO and the way they determine the strategy for the university (Shattock, 2002).

According to Barghet. al (1996) "Radical changes have taken place not only in the shape of higher education system and the scale and character of institutions but in the links between universities and society, culture, science and innovation. These changes have transformed the environment of governance." (Bargh et. al, 1996, p 12) What Barghet. al (1996) highlighted is an aspect of how much things have changed in the world today.

Pakistan is a developing country where there is a need for improved governance in all sectors of the country and higher education is one of the sectors. The education system in Pakistan has had slow progress since partition in 1947 , with very little being spent on education by the government. There is a lack of technical support and a strong political influence that has led to very little powers with the boards of governors of universities in the country of the public sector. The private sector universities have autonomy to some extent but that too in some cases is influenced politically.

In Pakistan, the issue of governance in higher education has gained importance in the last decade or so but the issue has never really been given proper attention despite some efforts. In 2001 with great enthusiasm and apparent support the reorganization of higher education in Pakistan began, but only after two years a stop was put to the reforms. There were several reasons for this break down, but the most prominent has been the lack of leadership at the highest level (Gilani, 2006).

Universities in Pakistan are faced with multiple challenges and the top management including the boards of governors seems to lack the expertise to face these challenges. There are problems with decision making at the highest level and whether the right decisions are being made in terms of quality assurance in universities in Pakistan, both in the public and the private sector.

According to the Task Force report of 2002, the issue of governance and management in universities in Pakistan has been described in the following words:

Universities are the pillars of the higher education system. They must have autonomy from all extraneous influences in order to govern and manage their academic, administrative, and financial functions. In particular, universities must have autonomy to develop their academic programmes; recruit, assess, and develop their faculty; and select, train and educate their students. The present organisational structure, including the Senates and Syndicates, has too many weaknesses of which the principal one is an inadequate 
separation of governance from the functions and responsibilities of management. In order to ensure accountability for institutional performance, each university must have a strong and independent governing or policy making body that may be called a Governing Board (GB) appointed by the Chancellor from candidates nominated by a nominating committee of the Board, and an independent system of management that is accountable to it. The Chief Executive Officer of the university (Vice Chancellor or Rector or President) must be identified through a formal and open search process, and appointed by the Chancellor from a selection of candidates recommended by the GB.

The above description has beautifully characterized what is to be required in order to have autonomous independent boards of governors in higher education institutions in Pakistan, but it does not describe how exactly it can be implemented. One important idea can be observed is the way the Syndicates and Boards of governors are structured.

The lack of governmental funding for higher education, increased international competition among universities and the dysfunctional governance, reviewers have questioned the existing structures of governance in the universities and whether they are quipped with dealing with all the changes (Trakman, 2008).

\subsection{Composition of Boards of Governors and their role}

University governing bodies have been a part of the culture, history and the structures of universities and their existence has been far from simple. Boards of governors have always been seen as having a representative role and there has been a debate about who should be on the boards between the 'internal' professional academics and the 'external' origins whose interests are derived by different reasoning and population (Bargh et. al, 1996: p 70).

Universities worldwide have seen a transformation in the way the overall culture and organizational structure of universities has been changed. The changes have been in the overall organizational behavior of universities to the way they are funded. There has been an increased inclination toward more competition and entrepreneurialism and had resulted in shifts in the operating activities of universities. There is a new era to the governance and management of universities where words like efficiency, resourcefulness, flexibility and responsiveness have become important and questions have been raised on the way the university governance operated before and there have been questions of the external and internal relationships of universities. These major changes in the setting of universities have led to a critical evaluation of the boards of governors and whether there is a need to radicalize boards. There has been a shift towards bringing in more people from business and industry on university boards to enlarge the scope of vision and to cope with the changes (Bargh et. al, 1996, p 70).

In Pakistan, like other countries in the world, the universities have a form of highest decision-making body to which the managers of the universities are held accountable. These university governing boards come in all forms and are given different names. They may be addressed as boards of trustees, administrative councils, university assemblies, senates, syndicates or something else. The orders, arrangement and procedures of university boards also differ, and so does the process of appointing the members. The decisions that are made in describing the characteristics of boards, often makes the difference between autonomous, responsive and imaginative leadership and restrictive, rigid and conformist administration - or something in the middle (Saint, 2009).

The public sector universities in Pakistan have a fair share of government involvement. According to the World Bank report, institutional autonomy is necessary for higher education to flourish, it can be held in check by the political economy of the state. High levels of state involvement in the management of higher education, or political intervention in institutional decision-making, can suppress innovation, encourage rent-seeking, and politicize the education system (Saint, 2009).

According to the Task Force Report (2002) that was structured to ensure better governance in Pakistan it was suggested that:

Effective policy making requires an enlightened Governing Board that has a broad view of the impact of higher education on society and is cognisant of the strategic directions and resources for achieving the university's mission with quality that is worthy of recognition nationally and internationally.

The university boards have different responsibilities, but all of them are tasked with defining a strategic vision for the institution, setting institutional policies, monitoring institutional performance, and ensuring good stewardship of institution's assets. Some of the boards are asked to take on responsibilities for quality assurance and the equivalence of academic awards. Others are allowed to define salary structures, terms of employment for academic staff, and/or recruitment of the institution's chief executive. A few are empowered to set student fees and determine student intake numbers. In general, higher levels of institutional autonomy can be found where boards are given more of these responsibilities (Saint, 2009). 
The appointment of board members is an important criterion in establishing the autonomy of the board. According to the World Bank report (2000), there are essentially four ways of appointing members on boards. They are (i) the Head of State or Prime Minister may control the selection directly; (ii) the Minister of (Higher) Education may be given appointing authority; (iii) a formula may be defined whereby various stakeholders or constituencies elect their representatives to service on the board; or (iv) Board Members may choose their own replacements through a self-perpetuating process. In practice, these four approaches are rarely found in pure form, and most countries employ a mix of these methods.

\subsection{Governing Boards in Public and Private Sector Universities in Pakistan}

In public sector universities in Pakistan there is the highest authoritative body, which is called the Senate. It is a rather large body and its main functions are to approve university laws, endorse budgets and in some cases, select candidates to become head of the university. It usually meets annually or bi-annually to perform these limited functions.

However in Pakistan, in addition to the Senate, there is a combined governance and executive body that is called a Syndicate and has 12-25 members. The Syndicate is a reflection of a governing board, which is found in private sector universities. The Syndicate acts like a governing board and performs similar tasks to such a board including the management of university assets, developing budges, making staff appointments etc. In Pakistan, the Head of the state appoints almost all members of the Syndicate even those who are chosen from the academic community(Saint, 2009).

Table 2 is a part of a larger table taken from the World Bank Report (2000). The data in the table depicts the composition of the board of governors, how they are appointed, external accountability and degree of autonomy. This information taken from the World Bank Report is regarding the Public sector universities in Pakistan.

According to the World Bank Report, it can be observed that Pakistan has a high level accountability of boards, but it is of a negative kind. This negativity is a reflection of the high governmental control on the appointment of board members of public sector universities. The Board of Governorshave a low degree of autonomy (Saint, 2009).

In explaining the composition of the public sector boards in Pakistan, it is clear that the Head of the State directly appoints all members of the boards and there is considerable governmental control on the administrative aspects of a typical public sector university (Saint, 2009).

Private universities in Pakistan have grown by a large number in the last two decades. However, at the one end the growth of such institutions provides more variety to students, there are some universities with questionable status.

The private university boards have known to mimic their public university counterparts. What this means is that if there is a small number of members on the board of a public university, there will be a small board in a private university as well in a particular country (Saint, 2009).

Table 2.

\begin{tabular}{lllllll}
\hline Country & $\begin{array}{l}\text { No. of } \\
\text { Members }\end{array}$ & Composition & How appointed & $\begin{array}{l}\text { External } \\
\text { Accountability }\end{array}$ & $\begin{array}{l}\text { Degree of } \\
\text { Autonomy }\end{array}$ \\
\hline Pakistan & $25-30$ & $\begin{array}{l}100 \% \text { appointed by } \\
\text { the Chancellor }\end{array}$ & $\begin{array}{l}\text { All by } \\
\text { political } \\
\text { authorities }\end{array}$ & High & Low \\
& & & & & \\
& & & & &
\end{tabular}

(Head of state or

governors)

Private university boards in Pakistan are more autonomous compared to public sector boards, and hence private universities have a better governance system. This is a clear contrast between the boards of the two sectors. This is because in private universities the founder or the owner of the institution appoints board members, instead of letting elected officials make decisions which is the case in public universities as has been discussed above.

Lahore University of Management Sciences (LUMS) is one of the private universities in Pakistan that has a fully functioning board of governors. The university website describes the duties of the board of trustees as:

The Board of Trustees, the policy-making body of the University, comprises leading members of the business community, academia and representatives of the government. The principal functions of the Board are to set broad policy guidelines and to review the operations of the University which functions on no profit no loss 
basis.

The Pakistani higher education system has traditionally been dominated by a domineering set of public universities and oversight bodies. However in the recent past there has been development in private universities with a number of individuals and corporate entities joining to form new universities. Private universities have proven to be a blessing for students and the overall system of education in the country (World Bank, 2000).

Universities like Aga Khan University (AKU) and Lahore University of Management Sciences (LUMS) have been a part of this altruistic gesture by private organizations.

In the case of the AKU, the goal of establishing a university was to improve the quality of life of disadvantaged Pakistanis through instruction and research in health sciences, education, and other fields. By contrast, LUMS was created to overcome problems of low quality in bureaucratic public universities and to help ensure a steady supply of well-trained business people. (World Bank, 2000)

These two private universities are a proof of excellence that private universities in the country have achieved. With the right amount of resources and appropriate good relations with the government, funding for these institutions is done in a timely manner.

However, on the other side there have been private sector universities that have not been very successful. The HEC recognized private institutions are the credible one. Unfortunately, a large number of illegal private universities and colleges operate throughout the country providing shady degrees. With HEC not recognizing such institutions, these unlawful universities and colleges lose all credibility (World Bank, 2000).

\subsection{The regulator of Higher Education in Pakistan and Quality Assurance}

In the last decade or so, like other developing countries, Pakistan has also been experiencing expansion in higher education institutions. The Higher Education Commission (HEC) has been the driving force in the promotion of higher education. However, the issue regarding quality assurance in higher education has not been taken into account with this increased expansion in the sector. The essential factor in this regard that needs to be considered is that having processes and framework for quality in higher education will contribute, but are not the only things to bring a change. What is required is for the people in-charge at the highest level of universities to bring a change in their mind-sets and attitudes so that the maximum amount of quality in higher education can be attained (Shah, 2010).

Higher education is a vast field and there are different ways to dealing with its regulation and to implementing a proper policy. Public policy seeks to define the characteristics of higher education and to explain performance expectations. Governments can decide how they want certain universities to take up tasks. Like, for example a government may decide that universities must undertake research and at the same time may provide a specific set of standards against which the quality of research will be analyzed (Blackmur, 2007).

Quality Assurance (QA) for the academia as well as the government and policy makers and essential regulation is to guarantee outcomes for the managing of higher education institutions (Moosa, 2006).

There are both intrinsic and extrinsic factors that derive quality in higher education institutions. What this means is that inspection and accountability are externally monitored, whereas teachers, a variety of programs etc. derives quality internally in universities (Shah, 2010).

According to Gilani (2006) who served on the Task Force, the reform efforts for higher education in Pakistan lost track due to two important factors. The first is the issue of the way the state operates. The decisions are made in a top-down hierarchical manner with no transparency and accountability. The TF had suggested for a Higher Education Commission to be formed which did become a reality with the formation of HEC in 2004. The higher education commission is functioning as any other bureaucracy of the country. The second issue was of course of the weak leadership of the universities (Gilani, 2006).

However, since then the Higher Education Commission of Pakistan has introduced a lot of reforms to ensure quality assurance in universities in Pakistan both in the public and the private sector. The reforms have been in the form of faculty development to structural changes in governance and management of higher education institutions. The idea behind all these initiatives by the HEC is to bring in quality in the teaching and research of universities, the centers of learning. However, quality may be seen as an end product for the reforming of higher education, it is in fact an essential factor for which systems and controls need to be developed both at the policy level and the operational level (Jadoon\&Jabeen, 2006).

Having established the importance of quality in higher education, the HEC developed a Quality Assurance Committee in 2003. The HEC has created a division for Quality Assurance to ensure that the policies for 
implementing quality programs are in place and being followed by universities (HEC Quality Assurance Division, 2011).

\subsection{Stakeholders of Higher Education and Quality Assurance:}

In order to analyze higher education and quality assurance, Kohler (2006) developed a simple framework of how the different interests of stakeholders are affected with reference to quality assurance.The analysis that is to be made is to see how better governance in universities can lead to better quality assurance of institutions. However, when considering quality assurance it has to be observed that what aspects of quality are being considered.

According to Kohler (2006), quality assurance in universities usually focuses on the selection and appointment of staff members, the different programs being offered, the overall level of the higher education institution, the quality processes that are being used and the overall system assessment.

When talking about the staff members in a university, in Pakistan in the public sector the ministry of education makes the appointment of the faculty members. The higher education commission provides a detailed criterion for the eligibility of faculty members in the universities. This criterion is for both the public and the private sector universities. However, in terms of the quality of faculty, this debate continues whether research should be the focus or should it be solely academic teaching.

Two main things categorize the programs offered by universities, one is the evaluating and accrediting quality of the programs being offered and it is a main tool to analyze quality assurance. The second is the idea of having standardized curricula that could be followed across the board (Kohler, 2006). In Pakistan, the regulator of higher education has an accreditation division where it is determined the affiliations of suitable foreign programs with programs in both the public and private sector universities (Accreditation Division of HEC, 2011).

The higher education institutions themselves act as projecting quality assurance practices with the kind of results a particular university has for a certain degree and the level of development that is being done in terms of research and the introduction of new programs (Kohler, 2006).

Quality processes deals with the improvement of the quality programs. It is to some extent related to the programs being provided but it highlights the conditions under which the program can actually be assessed through proper planning, implementation and the overall improvement activities (Kohler, 2006).

The system assessment is important in that it focuses on the overall reorganization of the higher education institution in a particular region. (Kohler, 2006) In Pakistan, in not so developed regions there are usually one or two main higher education institutions to provide quality education to the people of that area.

The factors described above give an idea of the different characteristics that can be used in assessing the quality of higher education institutions. However, these are internal assessment factors and their implementation leads to analysis being done by the external actors, including the different stakeholder, such as students.

The following figure 1 has been adapted from Kohler's (2006) depiction of how the five mentioned factors can be used to analyze the viewpoint of the actors involved. This chart has been formulated keeping in mind the context of Pakistan and the higher education scenario in the country.

The basic idea behind this figure is that four main elements have been considered and they are higher education institutions, the regulator the Higher Education Commission, the students and the last is the overall society. All these four elements are connected through the main component under focus and that is quality and quality assurance. The basic idea behind this chart is to assess the quality assurance in terms of internal and external factors and the different actors involved.

Looking at the higher education institutions it can be seen that it is up to the higher management to give a vision that is strategic and that ensures that the university will function in the best interest of the students by providing quality programs. When talking about the management, it is about the boards of governors of universities and how they provide a vision for introducing and then implementing quality assurance practices. Universities have this obligation to ensure that there is accountability and that they can be answerable for any policies that they are implementing and the reasons for implementation. The boards of governors are also required to ensure effectiveness and efficiency of their institutions. The Board of Governors also need to ensure that the right human, physical and financial assets have been used to achieve excellence in ensuring quality education (Task Force, 2002).

The higher education commission is the regulator and in order to check the quality of universities, the HEC has a quality assurance division. There is a quality assurance framework that has been developed by the HEC using international best practices on quality assurance (Appendix 1). This quality assurance framework provides a brief 
idea of how quality needs to be maintained and stresses the need for universities to monitor internally the quality assurance practices. The regulator is required to demand accountability from the universities and checking the overall effectiveness and efficiency of the universities.

The students are the ones who benefit from the high standards of universities and expect guaranteed quality for the money that they pay and want that there is a transparency in the system. By accepting the standards of universities there is an external acceptance on the part of the students.

The overall society has certain expectations from the government and the universities that affordable and quality education will be provided. The trust lies with the regulator to ensure the universities follow certain procedures for quality maintenance and there is a hope that universities would do the same.

Figure 1 is shown on the next page and it shows how these four elements discussed have an interrelated link with quality assurance.

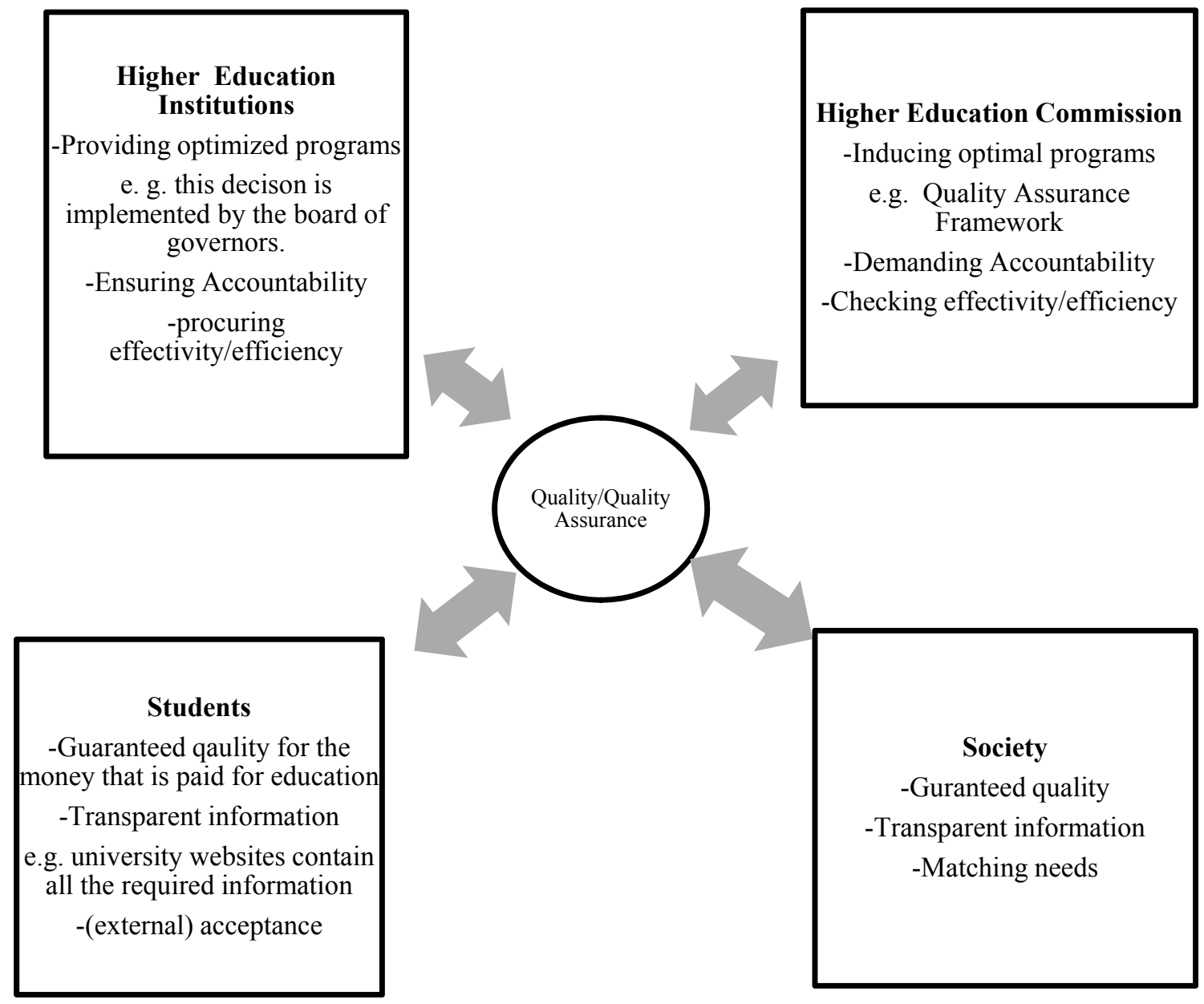

Figure 1.

For regulators of higher education quality improvement is an important facet to consider. On the other hand universities however, have the incentive to slow down their quality enhancement practices in order to reduce the rising expectations of the regulator. Keeping the true state of quality assurance practices that the university has adopted can do this (Blackmur, 2007).

Looking at the framework described above, there is a downside to the regulation of higher education. One of the factors to regulation of qualities and standards may lead to an increase in the extent of moral hazard inefficiencies in higher education. An example, maybe that the students and other stakeholders start having complete trust on the regulators and stop questioning or critically evaluating the methods the regulators use and the extent of their effectiveness. On the other hand, there could be effects on the credibility of the regulator, where the public and the stakeholders lose respect for it. This could be done if the regulator starts providing incomplete information that may 
be misleading, or if it performs inefficiently its administrative duties by implementing poor policies (Blackmur, 2007).

The chart adapted from Kohler's (2006) idea can also have a downside that has been discussed. Given this the regulator of higher education is also accountable for the policies that they implement.

In Pakistan, the issue of governance is critical and the top management of the universities needs to work in collaboration with the HEC to bring in quality assurance practices to the institutions. Looking at Kohler's (2006) model, it is very clear that the higher education institutions and the regulator need to work in collaboration, as all the four elements discussed are linked to quality assurance. If quality assurance is to be achieved, such a framework is required for Pakistani universities to function effectively.

\section{The Methodology}

\subsection{How the research was conducted}

The research for this paper was mostly secondary with few primary sources. The method used for primary research has been qualitative with interviews being conducted. For the purpose of this research, the views of the people interviewed shall remain anonymous.

This qualitative research study was conducted using secondary sources and supported with a number of interviews. Interviews $(\mathrm{n}=50)$ were conducted both telephonically and face to face, as well as via an electronic questionnaire distributed by email. Variations in data collection were due to time constraints and participant availability.

According to the Higher Education Commission Pakistan, there are a total of 136 universities and degree awarding institutions in Pakistan, 74 in the public sector and 62 in the private sector. (www.hec.gov.pk) Out of this total, 10 universities were chosen as a random sample: 5 universities from the public sector and 5 universities from the private sector. In choosing the 10 universities, effort was made to choose universities from all the provinces in Pakistan. However from the province, Punjab that is the hub of education, more universities were chosen from there.

The universities selected in the two sectors are shown in table 1, below:

Table 1.

\begin{tabular}{ll}
\hline Public Sector Universities & Private Sector Universities \\
\hline Punjab University (PU) & $\begin{array}{l}\text { Lahore University of Management Sciences } \\
\text { (LUMS) }\end{array}$ \\
Bahria University Islamabad & $\begin{array}{l}\text { National University of Computer and Emerging } \\
\text { Sciences (NUCES) }\end{array}$ \\
Government College University & Forman Christian College (A Chartered University) \\
Institute of Business Administration (IBA) & Aga Khan University (AKU) \\
University of Peshawar & GhulamIshaq Khan Institute of Technology (GIKI) \\
\hline
\end{tabular}

The organizational structures of the ten universities was analyzed and it was found that there was a concept of a board of governors in each of the universities but the level of autonomy that each had varied. The boards of the private sector universities were recognized to be fairly autonomous, whereas a strong governmental influence was highlighted for the boards of public sector universities.

The information regarding the university boards and charters in the case of private universities was taken from the respective websites of each university.

The people who were interviewed were asked questions about the overall structures of universities, the boards of governors, the decision making processes, the regulator and any overall issues they felt were prevalent in the higher education institutions that prevented proper governance and quality assurance.

The responses of the interviews and online questionnaire varied from individual to individual. Some academics showed great support for their respective university governance structures, while others were reluctant in saying much against the management. The reluctance was observed mostly in the public sector universities because the individuals being paid by the government felt obligated to the management and the code of conduct that they followed. After the compilation of the data, several common factors were identified regarding the governance of higher education in Pakistan. 


\subsection{Problems identified regarding Higher education policy and the Higher Education Commission}

One factor that was identified was that the higher education institutions were in confusion. The basic issue was that unfortunately to this date a coherent policy for higher education in the country has not been formulated at the national level. This has then led to the inability to handle the issue of governance in the country as no decision has been made on whether Federal or Provincial Governments should have authority over universities, whether universities should focus more on research than on teaching at this level, and whether there is a role for occupational education.

Leading from this point was the fact that the regulator in the country seems to be unsure of its role. The views however, regarding the Higher Education Commission were mixed. Some applauded the efforts of the HEC in terms of the work that it was doing in trying to streamline education and providing a framework for quality assurance. Others were of a different view stating that the HEC acted like any other bureaucracy in the country where the policies were made on the basis of a reaction to a problem rather than to actually finding the cause of the problem.

One problem that was identified in this respect was the HEC's policy classification for increasing PhDs in the higher education institutions in the country that has led to many academics havingsuspicious degrees. Further this way the complex categorization of research provided by HEC has led to the plague of plagiarism as academics in the struggle for more publications employed unethical tactics. However, in this respect the effort of HEC to recognize plagiarized cases has also been applauded. One issue regarding the higher education commission that was highlighted was that it was far from being an autonomous body as there is always some form of governmental pressure on the organization.

Quite a lot of issues were identified regarding the overall organizational structures of universities. One was the adoption of American-style baccalaureate degrees. At the one end international standards require four-year degrees, but universities in Pakistan have not been able to make the transition in terms of quality. Furthermore, the HEC encourages foreign affiliations, which to some level are attractive to students, but it also leads to universities forgetting their duty at the local level.

Otherissues that were recognized include, the colleges that have been converted to universities have been unable to cope with the structural change. Further, public sector universities being transformed to private sector universities have also been struggling, as there has been no firm financial support for them to progress effectively.

\subsection{Problems of Governance in Universities}

Having identified the structural issues, the governance and management problems were then highlighted. The board of governors of universities seems unaware of the structural issues of universities. This leads to universities unable to cope with the challenges of the $21^{\text {st }}$ century. These include the evolution of new markets and the creation of new opportunities; the shift from teaching institutions to learning organizations; and the emergence of new professions and vocations.

Hence, the interviews helped identify three main issues of governance: one at the structural level, the second at the academic level and the third at the organizational level.

The structural level reflects the fact that universities both in the public and private sectors are expanding, and increasing disciplines leading to a number of different faculties and schools. The problem is that the universities remain so overly centralized that the decision-making remains distorted. There is a need for decentralization in terms of decision-making. One academic pointed that, 'over-centralization destroys initiative, leads to many missed opportunities, distorts the distribution of resources, and reflects badly on the quality of human resources available at the highest level.'

On an academic level there is a need to find the right balance between research and teaching, since research is essential for the development of faculty and the improvement of teaching. Unfortunately in majority of the universities in Pakistan, emphasis is only placed on teaching leading to large class sizes and high teaching loads, leaving no room for proper research.

On an organizational level, there is dominance of the different layers in the management with committees and inefficient teams in place of proper systems and controls. The problem is that usually, the managerial power rests with one particular individual and the committees are a way that brings a ruin to the organizational democracy. These committees are large and not very efficient, which results in a delayed decision-making process. Furthermore, the appointment of members on these committees is usually on patronage than on merit and that leaves no room for any transparency. 
Having described these issues, the simple fact is that no regulatory framework is in place that would ensure that the board members of universities undergo some kind of training, so that they can act as trustees of universities instead of being unaware of all the organizational issues and making the wrong decisions.

\subsection{Problems in the selection of the Board of Governors of Universities}

In most of the private and public sector universities in Pakistan, the boards of governors are a combination of alumni, donors, appointees, public figures, government nominees etc. It is very rare to find a member on the board being appointed because he/she possesses the knowledge of how universities need to perform, or because he/she has outstanding academic contribution.

Due to this distorted appointment of board members, a critical consequence is that the boards become very dependent on the CEO. What happens is that since the boards function in an inefficient way, the senior management exploits the information provided by assuming too much power. Thus the management style becomes very personalized and the institutional vision ends up being a reflection of one particular individual. The CEO exploits the power so much that any questions asked by any board members against the decisions, leads to the removal of that member and appointment of the one sharing similar ideas to the CEO.

The CEO ends up having so much power that he/she uses that power to be free of any checks and balances that maybe imposed by a board that asks too much questions, by having an overly centralized system of decision-making. With all the decision-making being overly centralized, the CEO ends up taking responsibility for even the most trivial administrative tasks. What this means is that too much power in the hands of the CEO leads to the CEO having a seriously limited strategic role. There is no delegation of power by the CEO and when he makes all the decisions, it results in flawed management and a series of problems on an institutional level for the university.

Further, in order to perpetuate the role of CEO, and the hierarchy that is present in such an organizational structure of a university, all individual appointments are made on how well those individuals rubber stamp the decisions of the CEO. Unfortunately, the recruitment of members is on the bases of maintaining a status quo then to bring in more innovation and a fresh thinking to the board.

As a result, any criticism that may be present for any decision to be voiced is not allowed, resulting in committees and teams unable to make proper decisions as all the power rests with the CEO. This results in the organization having a low performance and the motivation deriving the management rests in perks and benefits. With all the benefits, the senior management just follows the status quo. This leads to a blurred organizational mission and in following the status quo, the overall motivation and commitment suffers. This effects the organization as a whole and it fails to keep par with the changing market trends.

All these findings portray that in Pakistan, due to these structural imbalances, there are a number of higher education institutions that are unable to cope with the changing trends and end up providing poor quality education to students who pay so much.

One unfortunate trend that was voiced by the academics was that the commitment of the teachers also waivers, with one teacher teaching in more than one institution and not being able to give a $100 \%$ commitment to any one of the universities they are teaching at. In the public sector, increased governmental interference in the administrative matters leads to low level of integrity for the institutions where preferences are given in terms of admission criteria, hiring of faculty members and leading to a low quality of overall education.

From all of the above issues that were highlighted by talking to the academics regarding the governance of universities in Pakistan both in the public and the private sector, the main problems have been highlighted.

\section{Recommendations and Conclusion}

From the above case and the discussion following it, the problems associated with the structure of boards of governors of both public and private sector universities in Pakistan have been analyzed with a view of quality assurance. However, the problems have been identified and leave room for a lot of improvement in the higher education sector of the country.

The above discussion has clearly pointed to the fact that the higher education system in Pakistan is far from developed. The issue of governance and the role of boards of governors in both the public and the private sectors are critical and there is a need for better management to ensure quality assurance.

According to Iqbal (2004), there are major gaps in the quality of faculty, the governance, the academic programs, the excellence of students, research facilities, proper libraries and labs. Unfortunately, the higher education system in the 
country is not at par with international standards leaving a dearth of qualified graduates who can help with the rebuilding of the higher education institutions.

The flaws and the issues of the system have been recognized. The question that remains is that how can there be a change in the system? What needs to be done to ensure that there is an improvement in the governance structures of universities both in the public and the private sectors?

Change at this level does not imply that there is need for a different, novel policy altogether or the total revamping of the entire organizational structures of the universities (Ahmed, 2008). There are some policies that are on the right path; they just need to be implemented more effectively to bring in a positive change. The HEC as the regulator of higher education has introduced quality assurance mechanisms that need to be followed more diligently.

According to Ahmed (2008), in order to improve the university effectiveness, there is a need to examine each activity as a whole. Universities are complex organizations as has been discussed earlier and each part of this complex organization is dependent on the other. What this means is that the university having successful graduates is dependent on the quality of the teachers and the programs that the university offers.

In order to improve governance and management, there needs to be training and education of a large number of academics in the management issues of higher education institutions and how to bring the change that is needed (Ahmed, 2008). The fact is that there is not need for a delay where when the members of the boards of governors are selected and they are clueless about what they are supposed to be doing. If individuals are trained before hand, they can better perform their roles as trustees of universities.

For private universities, the change is easier, as there is a fair amount of autonomy for governance, for the selection of members on the boards and for there to be succession plans in place to ensure that there will be a smooth transition of the top management.

Another way to ensure quality at the highest level of education is to revise the Charters and statutes of universities so that there can be clauses to change the composition of the boards of governors (Ahmed, 2008).

University boards in the private sector in Pakistan are to a certain degree working much more efficiently than the boards of public sector universities. Having autonomy and corporate style boards, the private sector universities in the country provide better programs and there is a certain degree of quality assurance that is absent in the public sector.

There is a need for the public sector boards to be re-modeled to be able to cope with the changes and to be able to provide good governance. However, the modeling of a brand new governance structure for the universities requires continuous commitment where the institutional structure in not changes to such a degree that it becomes difficult to recognize the values on which it was built. It should also be kept in mind that the revamping of public sector university boards will have political implications which need to be considered before a re-modeling begins (Trakman, 2002).

Having said this, change cannot be brought overnight. The existing governing boards will resist to the re-modeling. In order to avoid that, the members of the boards need to be made aware that they are agents of higher education in the country and it is there duty to ensure better governance for universities.

According to Dearlove (2002), 'universities are innovative when it comes to piecemeal and incremental change, but deeply conservative when it comes to actually implementing systemic change across the whole of an institution.'

For restructuring of university governance in Pakistan, there is a need for both incremental and strategic change. Incremental change happens slowly. This change is essential for Pakistani universities because, there is a need to improve the quality of faculty and the programs being offered and that can only happen overtime. There has been an increase of masters and PhD level graduates in the country in the last 5-6 years with the help of the HEC. The HEC provides scholarships to deserving candidates who get the opportunity to study within Pakistan and at the international level (Scholarship Schemes by HEC, 2011).

However, this scheme is dependent on the funds available to the HEC by the government, and when government funds stop, the scholarship programs have to be seized. The downside to this is that even though this initiative is great, it sometimes leaves students helpless when the HEC cannot provide them the funds. This system needs to be analyzed as well to ensure that there are sufficient funds available.

Universities in Pakistan need strategic and organization change as well which is a lot harder than incremental change. What this means is that there should be quality programs in universities and programs that are not productive should 
be shut down so that better quality programs can be introduced. The downside to strategic change is that academics are not ready to give up their research and that can hinder this kind of change (Dearlove, 2002).

One way the boards of governors of the public sector universities can be restructured is to maybe follow the private sector practices of governance. The downside to such a decision is that, the private sector policies may seem attractive; they cannot guarantee that there will be successful if implemented in the public sector (Bennet, 2002).

The bottom line is that there are major issues in governance of universities in Pakistan both in the public and the private sector. The private sector universities are still performing much more effectively than their public sector counterparts. The reasons for this are clearly linked to the level of autonomy that the private sector enjoys, the degree of transparency employed in the appointment of the members of the boards of governors and the importance that is placed on quality in the private sector. As a result, the private sector universities in Pakistan are performing in a much better way than the public sector universities, which lack autonomy, function as bureaucracies and lack proper governance.

The research for this paper has been limited due to time constraint, but the main factors have been identified in both the public and the private sector universities in the country in terms of governance and quality assurance. Recommendations have also been given and are focused on the need for a restructuring of the higher education institutions holistically. These recommendations are far from complete and there is plenty that can be done to have effective boards of governors in public sector universities especially so that there is improved quality of education.

\section{References}

Aga Khan University (AKU). (2011). [Online] Available: http://www.aku.edu/university/bot/index.shtml (July 20, 2011)

Ahmed, N., S. (2008). 'The Role of Governance and Its Influence on Quality Enhancing Mechanisms in Higher Education,' Business Review, Research Journal of Institute of Business Administration Karachi-Pakistan, 3:1pp 145-151.

Bahria University Islamabad. (2011).[Online] Available:http://www.bci.edu.pk/bog.aspx, (July 20, 2011)

Bargh, Catherine, Scott, Peter, \& Smith, David. (1996). Governing Universities: Changing the Culture (Buckingham; Bristol, PA., USA: Society for Research into Higher Education and Open University Press, 1996). PMid:8765481.

Bilal, M., \& Khan, I. (2012, November). 'Issues and Prospects Behind the Depressed Higher Education in Pakistan', Interdisciplinary Journal of Contemporary Research in Business, 4:7pp 157-172.

Blackmur, Douglas. (2007). 'The Public Regulation of Higher Education Qualities: Rationale, Processes and Outcomes,' in Quality Assurance in Higher Education: Trends in Regulation, Translation and Transformation, Don F. Westerheijen, Bjorn Stensaker and Maria Joao Rosa, (Dordrech; London: Springer 2007) pp 15-45.

Bennet, B. (2002). 'The New Style Boards of Governors - Are they Working?' Higher Education Quarterly, 56:3 pp 287-302.

Cohen, MD, March, JG \& Olsen, JH.(1972). 'A Garbage Can Model of Organizational Choice' Administrative Science Quarterly, 17(1): 1-25.http://dx.doi.org/10.2307/2392088

Dearlove, J. (2002). 'A continuing Role for Academics: The Governance of UK Universities in the Post-Dearing Era,' Higher Education Quarterly, 56:3 pp 257-275.

Forman Christian College (A Chartered University). (2011).[Online] Available:http://www.fccollege.edu.pk/about/rectors-office/board-of-governors, (July 20, 2011)

GhulamIshaq Khan Institute of Technology (GIKI). (2011). [Online] Available: http://www.giki.edu.pk/About\%20GIKI/AboutGIKIBoardOfGovernors.htm(July 20, 2011)

Gilani, S. Zulfiqar. (2006). 'Problems of Leadership and Reform in Pakistan,' International Higher Education, Winter 2006, No. 42.

Government College University. (2011). [Online] Available: http://www.gcu.edu.pk/Univ_Auth.htm, (July 20, 2011).

Harvey, L. (2004-11). Analytic Quality Glossary, Quality Research International, [Online] Available:http://www.qualityresearchinternational.com/glossary/governance.htm, (August 01, 2011)

Higher Education Commission Pakistan. (2011). [Online] Available: http://www.hec.gov.pk/Pages/main.aspx, (July 20, 2011) 
Hoodbhoy, Pervez. (2009). Pakistan's Higher Education System - What went wrong and how to fix it, The Pakistan Development Review, [Online] Available:http://pide.org.pk/pdr/index.php/pdr/article/viewFile/2643/2610 (February 25, 2014)

Human Development Sector South Asia Region The World Bank, Pakistan: An Assessment of the Medium-Term Development Framework, Higher Education Policy Note Report No. 37247, (June 28, 2006)

Institute of Business Administration (IBA). (2011). [Online] Available: http://www.iba.edu.pk/patron.asp\#BOG, (July 20, 2011)

Iqbal, A. (2004). 'Problems and Prospects of Higher Education in Pakistan', PhD, University of Arid Agriculture/Institute of Education and Research, 2004

Jadoon, I., Z. \& Jabeen, N. (2006, December). 'Human Resource Management and Quality Assurance in Public Sector Universities of Pakistan: The Case of Punjab University.' Paper presented at First International Conference on Assessing Quality in Higher Education (ICAQHE) 2006: Prosperity Through Quality Education, Lahore, Pakistan. PMCid:PMC1994747

Lahore University of Management Science (LUMS). (2011). [Online] Available:http://lums.edu.pk/about-lums/board-of-governors.php, (July 20, 2011)

Kohler, Jürgen. (2006). 'Quality Assurance: Role, responsibilities and means of public authorities, and the implications for Governance of Institutions and systems,' Paper presented at the Council of Europe Higher Education Forum: The Legitimacy of Quality Assurance in Higher Education: The Role of Public Authorities and Institutions (pp 16-29) Strasbourg.

Moosa, Kamran. (2006, December). 'Quality Assurance in Higher Education: Successful Approaches for Improving Quality in Colleges and Universities,' Paper presented at First International Conference on Assessing Quality in Higher Education (ICAQHE) 2006: Prosperity Through Quality Education, Lahore, Pakistan National University of Computer and Emerging Sciences (NUCES).[Online] Available:http://www.nu.edu.pk/Governers.aspx, (July 20, 2011)

Nordic Recognition Information Centers. (2006). Report on the System of Education in Pakistan, October, 2006.

Peters, G. (2002). 'Governance: A Garbage Can Perspective,' HIS Political Science Series: 2002, No. 84

Saint, William. (2009). 'Guiding Universities: Governance and Management Arrangements around the Globe,' Commissioned by the Human Development Network World Bank, (October 20, 2009).

Shah, Saeeda. (2010, December).'Higher Education Expansion in Pakistan and Issues of Quality, 3rd International Conference on Assessing Quality in Higher Education, Lahore, Pakistan.

Shattock, Michael. (2002).'Re-Balancing Modern Concepts of University Governance,' Higher education Quarterly, $56: 3$ pp 235-244.

Task Force on Improvement of Higher Education in Pakistan, March 2002, [Online] Available: http://www.tfhe.net/resources/pakistan.htm\#3, (August 10, 2011)

Trackman, Leon. (2008). 'Modelling University Governance' Higher Education Quarterly, 62:1/2 pp 63-83.

The International Bank for Reconstruction and Development/World Bank, Higher Education if Developing Countries: Peril and Promise, The Task Force of Higher Education and Society by the World Bank, 2000.

University of Peshawar. (2011). [Online] Available: http://www.upesh.edu.pk/Administration/statutery_body.html, (July 20, 2011)

University of the Punjab. (2011). [Online] Available: http://pu.edu.pk/home/Admin_structure/, (July 20, 2011)

\section{Appendices}

Quality Assurance Framework Provided by the Higher education Commission. 